\title{
Lightning mapping observation of a terrestrial gamma-ray flash
}

\author{
Gaopeng Lu, ${ }^{1}$ Richard J. Blakeslee, ${ }^{2}$ Jingbo Li, ${ }^{1}$ David M. Smith, ${ }^{3}$ Xuan-Min Shao, ${ }^{4}$ \\ Eugene W. McCaul, ${ }^{5}$ Dennis E. Buechler, ${ }^{6}$ Hugh J. Christian, ${ }^{6}$ John M. Hall, ${ }^{6}$ \\ and Steven A. Cummer ${ }^{1}$
}

Received 6 April 2010; revised 26 April 2010; accepted 28 April 2010; published 8 June 2010.

[1] We report the observation with the North Alabama Lightning Mapping Array (LMA) related to a terrestrial gamma-ray flash (TGF) detected by RHESSI on 26 July 2008. The LMA data explicitly show the TGF was produced during the initial development of a compact intracloud (IC) lightning flash between a negative charge region centered at about $8.5 \mathrm{~km}$ above sea level $\left(-22^{\circ} \mathrm{C}\right.$ temperature level) a higher positive region centered at $13 \mathrm{~km}$, both confined to the convective core of an isolated storm in close proximity to the RHESSI footprint. After the occurrence of an LMA source with a high peak power $(26 \mathrm{~kW})$, the initial lightning evolution caused an unusually large IC current moment that became detectable $2 \mathrm{~ms}$ after the first LMA source and increased for another $2 \mathrm{~ms}$, during which the burst of gamma-rays was produced. This slowly building current moment was most likely associated with the upward leader progression, which produced an uncommonly large IC charge moment change $(+90 \mathrm{C} \cdot \mathrm{km})$ in $3 \mathrm{~ms}$ while being punctuated by a sequence of fast discharge. These observations suggest that the leader development may be involved in the TGF production. Citation: Lu, G., R. J. Blakeslee, J. Li, D. M. Smith, X.-M. Shao, E. W. McCaul, D. E. Buechler, H. J. Christian, J. M. Hall, and S. A. Cummer (2010), Lightning mapping observation of a terrestrial gamma-ray flash, Geophys. Res. Lett., 37, L11806, doi:10.1029/ 2010GL043494.

\section{Introduction}

[2] Terrestrial gamma-ray flashes (TGFs) are short bursts of energetic photons that escape the atmosphere to be observed by space-borne detectors in low Earth orbit [Fishman et al., 1994; Smith et al., 2005]. With energies of $10 \mathrm{MeV}$ and higher, TGFs are attributed to bremsstrahlung radiation from relativistic runaway electrons scattered by nuclei of air molecules [Gurevich et al., 1992], and their connection with lightning discharges is documented by detecting low frequency radio emissions [Inan et al., 1996,

\footnotetext{
${ }^{1}$ Electrical and Computer Engineering Department, Duke University, Durham, North Carolina, USA.

${ }^{2}$ Earth Science Office, NASA Marshall Space Flight Center, Huntsville, Alabama, USA.

${ }^{3}$ Department of Physics and Santa Cruz Institute for Particle Physics, University of California, Santa Cruz, California, USA.

${ }^{4}$ Space and Remote Sensing Group, Los Alamos National Laboratory, Los Alamos, New Mexico, USA.

${ }^{5}$ Universities Space Research Association, Huntsville, Alabama, USA.

${ }^{6}$ Global Hydrology and Climate Center, University of Alabama, Huntsville, Alabama, USA.
}

Copyright 2010 by the American Geophysical Union. 0094-8276/10/2010GL043494
2006; Cummer et al., 2005; Stanley et al., 2006; Cohen et al., 2010; Shao et al., 2010].

[3] Although originally thought to be high altitude (30$50 \mathrm{~km}$ ) processes driven by positive cloud-to-ground (CG) strokes transferring positive charge to ground [Fishman et al., 1994; Inan et al., 1996], detailed lightning measurements [Stanley et al., 2006; Shao et al., 2010] and spectral analyses [Dwyer and Smith, 2005] suggest that TGFs are produced below $21 \mathrm{~km}$, most likely in association with intracloud (IC) lightning discharges [Stanley et al., 2006; Williams et al., 2006], such as those during the initial development of normal polarity IC flashes that raise negative charge in thunderclouds [Shao and Krehbiel, 1996; Shao et al., 2010]. Bursts of lightning-related energetic radiation occasionally in excess of $1 \mathrm{MeV}$ have also been observed at ground level in association with natural and triggered negative CG flashes [Moore et al., 2001; Dwyer et al., 2004], where coordinated measurements suggest they are related to downward negative leaders. The satellite-based TGF detections, however, are relatively infrequent and small timing uncertainty $(1-2 \mathrm{~ms})$ in the measurements aboard the Reuven Ramaty High Energy Solar Spectroscopic Imager (RHESSI) satellite [Grefenstette et al., 2009] has made it difficult to determine the precise temporal relationship between TGFs and lightning discharges, and many details regarding this correlation remain unclear. The one-time calibration against the Swift satellite with the observations of a cosmic gamma-ray event on 27 December 2004 fixed the RHESSI clock to $200 \mu \mathrm{s}$, while whether there is any larger remaining RHESSI timing uncertainty depends on if this correction fixed a permanent offset or a time-varying error [Grefenstette et al., 2009].

[4] We present the observation with the North Alabama Lightning Mapping Array (LMA) [Goodman et al., 2005] related to a TGF detected by RHESSI. For the first time a TGF is investigated in the context of the time-resolved lightning evolution. The LMA data explicitly show the burst of gamma-rays was produced during the initial development of an intracloud lightning flash, and the upward leader development may be involved in the TGF production. The remote measurements of electric and magnetic fields provide additional information to characterize the TGF-associated lightning process.

\section{Data and Observations}

[5] On 26 July 2008, RHESSI detected a TGF while passing over Nashville, Tennessee, at $560 \mathrm{~km}$ altitude. The first $\mathrm{MeV}$ photon was detected at about 09:38:16.2738 Universal Time (UT) using the corrected RHESSI timing, and the burst of gamma-rays lasted approximately $0.2 \mathrm{~ms}$. 

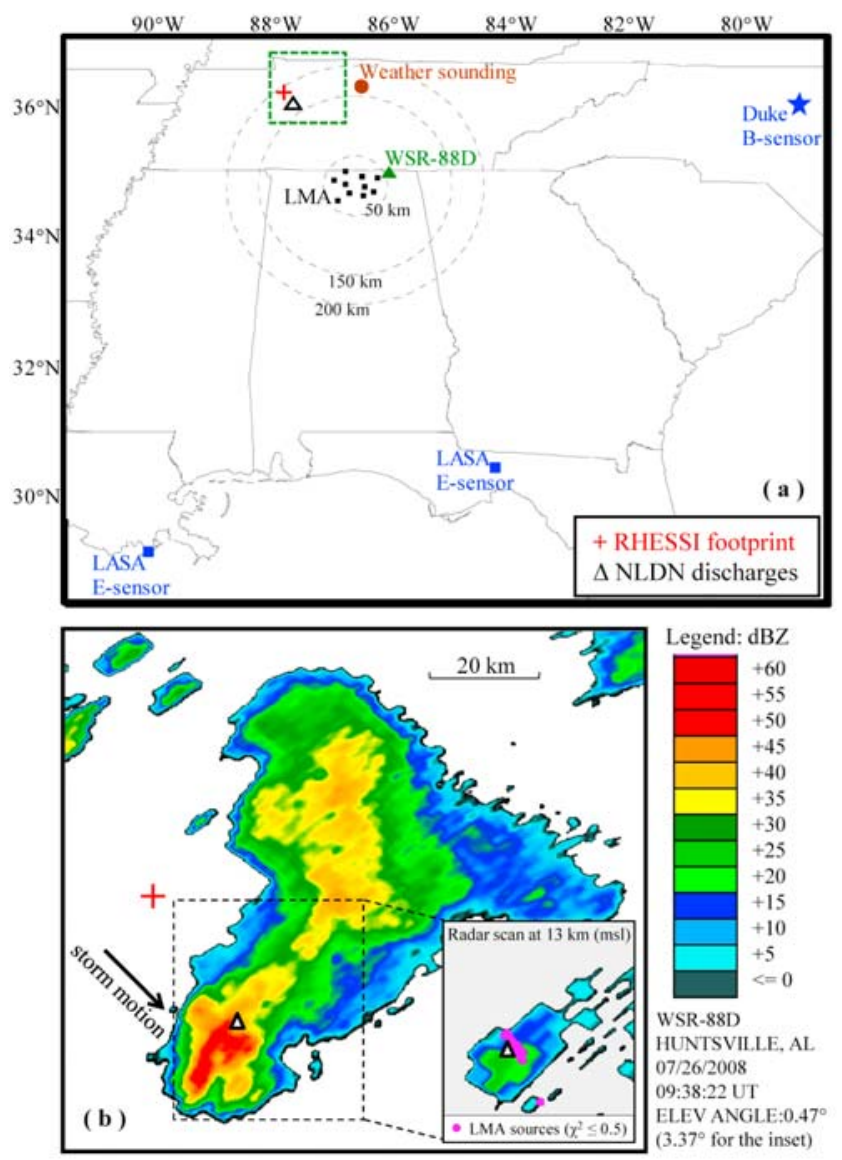

Figure 1. (a) Measurements related to a TGF detected by RHESSI over Nashville, Tennessee on 26 July 2008. (b) Precipitation reflectivity in the thunderstorm that produced the TGF-associated lightning flash, as observed by the meteorological radar located in Huntsville, Alabama. The elevation angle of the scan is $0.47^{\circ}$, toward an altitude of about $3.6 \mathrm{~km}$ (above sea level) in the convective region. The inset of Figure 1b shows the reliably-located LMA sources (in pink color) of the TGF-producing IC flash overlaid on a radar scan at $3.37^{\circ}$ elevation angle, toward the convective region at about $13 \mathrm{~km}$ altitude.

The unusually large fraction (70\%) of photons with energies $>1 \mathrm{MeV}$ implies a beamed source near the subsatellite point $\left(36.156^{\circ} \mathrm{N}, 87.883^{\circ} \mathrm{W}\right)$ [Hazelton et al., 2009].

[6] The measurements related to this TGF are summarized in Figure 1a. Among several storms shown by the meteorological radar, an isolated storm manifests itself with three lightning discharges located by the U.S. National Lightning Detection Network (NLDN) [Cummins et al., 1998] within $30 \mathrm{~km}$ of the subsatellite point. With the largest peak current $(+36 \mathrm{kA})$ of the three, the second NLDN discharge occurred within $1 \mathrm{~ms}$ of the TGF, and was almost certainly a positive IC discharge for the reasons discussed below but was classified as a positive CG stroke. The radar scan at $0.47^{\circ}$ elevation angle (Figure $1 \mathrm{~b}$ ) shows the lightning flash spawning these discharges was produced in the convective region of the storm, which exhibited some features of a supercell [Doviak and Zrnić, 2006, pp. 293-301]. The time history of this IC flash was recorded by the North Alabama LMA, which locates the sources of very high-frequency (VHF) emissions in the 76-82 MHz band with 11 receivers over an $80-\mathrm{km}$ diameter region centered on Huntsville, Alabama [Goodman et al., 2005]. Low frequency electric and magnetic fields for the TGF were measured at two sensors of the Los Alamos Sferic Array (LASA) and at a field site near Duke University, respectively.

[7] The inset of Figure 1b shows the radar scan at $3.37^{\circ}$ elevation angle toward the storm region at $13 \mathrm{~km}$ altitude above mean sea level (msl), where a contour of $20-\mathrm{dBZ}$ formed 5 minutes before the TGF, indicative of a strong updraft in the convective region. Radar scans at higher elevation angles (not shown) indicate that the cloud top with $>0 \mathrm{dBZ}$ reflectivity was between 13 and $16 \mathrm{~km}$, consistent with the height $(15.5 \mathrm{~km})$ of the local tropopause inferred from the radiosonde soundings (see Figure 2b).

[8] Figure 2a shows the LMA measurements of the TGFproducing IC flash, containing $41 \mathrm{VHF}$ sources detected within $230 \mathrm{~ms}$. At $170 \mathrm{~km}$ distance from the LMA origin, nearly all of these sources would have been produced by negative leaders that propagated into positive charge regions [Rison et al., 1999]. The computed locations of many of these sources are of relatively large uncertainty $(\sim 5 \mathrm{~km})$, mainly in radial distance and altitude [Koshak et al., 2004]. The LMA sources that were reliably located (i.e., with chisquare values $\chi^{2} \leq 0.5$ ), however, still depict the development of a bi-level IC flash in the upper part of the storm. These sources overlaid on the radar scan at $13 \mathrm{~km}$ (the inset of Figure $1 \mathrm{~b}$ ) indicate a compact IC flash confined to the convective region. The remaining LMA sources with $\chi^{2}>$ 0.5 , including all the sources above $15 \mathrm{~km}$, are less reliably located but still provide valuable information regarding the lightning evolution because the timing accuracy of LMA sources is typically better than $10 \mu \mathrm{s}$.

[9] RHESSI observed the TGF around the time of the first several LMA sources, which for an IC flash are usually associated with the initial negative leader that propagates

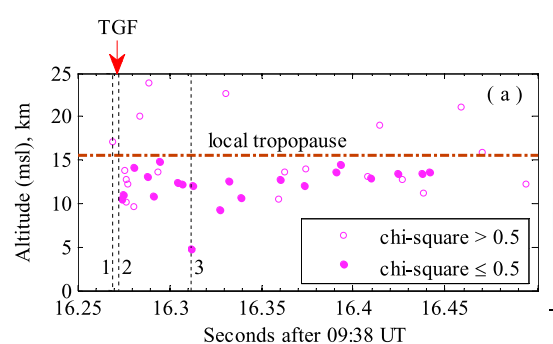

Nashville radiosonde sounding $(07 / 26 / 2008)$

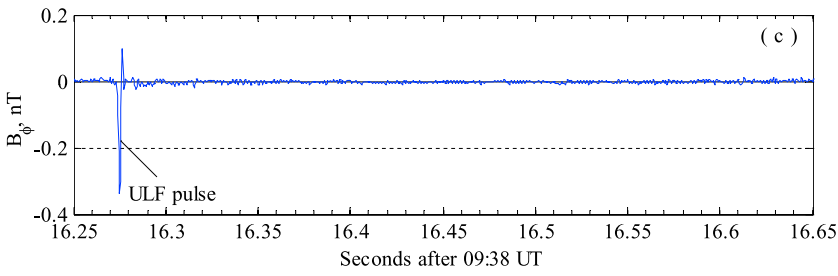

Figure 2. Comparison between (a) the time-resolved IC flash evolution mapped by the North Alabama LMA and (c) the low frequency magnetic field recorded near Duke University. The initial development of the IC flash caused a distinct ULF pulse. In Figure 2a, three lightning discharges detected by the NLDN for this flash are indicated, and the height $(15.5 \mathrm{~km})$ of local tropopause is inferred from (b) the radiosonde soundings near Nashville. 


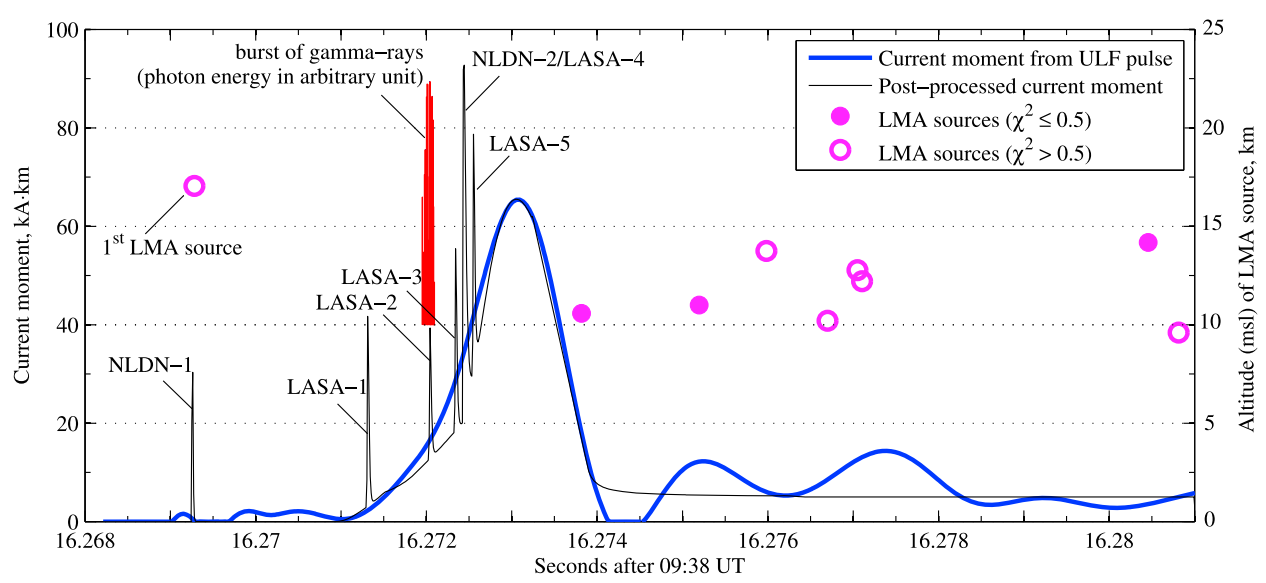

Figure 3. Comparison between the TGF production (in the source region), current moment waveform along a vertical lightning channel that extended from $1.5 \mathrm{~km}$ to $2 \mathrm{~km}$ in length, and the initial IC flash development depicted with the LMA sources in the first $12 \mathrm{~ms}$ time interval. Fast discharging processes detected by the NLDN and the LASA sensors are shown by narrow pulses superposed on the slowly building current moment extracted from the ULF pulse.

upward from the lower negative to the upper positive layer [Shao and Krehbiel, 1996]. The subsequent horizontal progression between 12 and $15 \mathrm{~km}$ indicates major positive charge concentrations in this region [Coleman et al., 2003]. The negative charge region is inferred to be between 7 and $10 \mathrm{~km}$ because the LMA observations of negative CG flashes in the same thunderstorm indicate that negative charge transported to ground was mainly from this range. A negative charge layer centered at $8.5 \mathrm{~km}$ is consistent with the typical temperature level $\left(-22^{\circ} \mathrm{C}\right)$ of the major negative charge region in supercell updrafts, and it is about $2 \mathrm{~km}$ higher than the main negative charge region in other types of thunderstorms in North America [Stolzenburg et al., 1998]. Both charge layers that were involved in the TGF-producing IC flash are sketched in Figure $2 b$.

[10] The initial IC flash evolution caused a distinct ultra low-frequency (ULF) pulse in the low frequency $(<0.1 \mathrm{~Hz}$ to $400 \mathrm{~Hz}$ ) magnetic field recorded at a distance of $\sim 800 \mathrm{~km}$ (Figure 2c). The negative polarity of this pulse is consistent with an upward transfer of negative charge in normal IC flashes. For most of the IC flashes in the same storm between 06:00 UT and 10:20 UT, the NLDN detected lightning discharges during the initial stage with peak currents ranging from a few $\mathrm{kA}$ to $+70 \mathrm{kA}$. Analysis of low frequency signals related to about 300 IC flashes suggests that while an ULF pulse during the initial flash development was present in $>90 \%$ of these flashes, the TGFassociated pulse is one of the strongest and is stronger than the typical by a factor of $>5$.

[11] In addition to a distinct ULF pulse, the initial development of the TGF-producing flash featured an initial LMA source with a peak power of $26 \mathrm{~kW}$, in comparison with $8-700 \mathrm{~W}$ for other sources in this flash. As shown in Figure 2a, the first LMA source was essentially simultaneous to the first NLDN discharge with $+20 \mathrm{kA}$ peak current. Similar events early in IC flashes with peak powers in excess of $100 \mathrm{~kW}$ may occur with narrow bipolar events (NBEs) between opposite charge layers in active storms [Thomas et al., 2001], while we are not sure whether that is the case here due to the lack of appropriate measurements. Initial LMA sources with a strikingly high peak power are observed for many IC flashes in the same storm although the ULF pulse early in these flashes was not as large as the one indicated in Figure 2c. Therefore, an unusually large ULF pulse during the initial stage seems to be the most distinctive feature of the TGF-producing flash. During the four minutes interval (between 09:36 UT and 09:40 UT) when the subsatellite point was within $800 \mathrm{~km}$ of the storm, there were four other IC flashes that demonstrated clear ULF pulses early in the flash. The magnitude of these ULF pulses ranged between 0.15 and 0.5 of the TGF-associated pulse indicated in Figure 2c. RHESSI did not report TGFs for these flashes using the search algorithm described by Grefenstette et al. [2009].

[12] Despite a high peak power, the first LMA source was located with the detections at only seven receivers. The relatively large chi-square value $\left(\chi^{2}=1.67\right)$ implies that the computed altitude $(17 \mathrm{~km})$ is very unreliable, likely due to the saturation at one or more receivers, and/or the inherent complicated radiation of the source [Thomas et al., 2001]. As the first LMA source is believed to be associated with the IC flash initiation between the charge layers sketched in Figure $2 \mathrm{~b}$, we estimate its altitude to be $10 \mathrm{~km}$. About $5 \mathrm{~ms}$ later, the second LMA source was located reliably (with $\chi^{2}=0.14$ ) at $10.5 \mathrm{~km}$ using the measurements at ten VHF receivers.

\section{Analyses and Discussions}

[13] From the low frequency magnetic field measurement we extract the time-resolved current moment (i.e., the product of the source current and the discharging channel length) [Cummer and Inan, 2000] with a resolution limited by the $400 \mathrm{~Hz}$ upper limit of the sensor. A second and more realistic waveform is estimated by incorporating additional measurements. Together, the NLDN detections and the LASA measurements available in a $3-\mathrm{ms}$ time window triggered by the second NLDN discharge, both with submillisecond accuracy, indicate the occurrence of at least 6 discrete fast discharges during the $5 \mathrm{~ms}$ interval after the first LMA source. The times, durations, and amplitudes of these discharges (relative to the NLDN discharges), as 
inferred mainly from the LASA data, are included in the modified current moment waveform. To scale peak currents reported by the NLDN to peak current moments, we assume all these discharges extended vertically between the negative charge region centered at $8.5 \mathrm{~km}$ altitude and the leader tip mapped by the LMA, whose altitude varied from $10 \mathrm{~km}$ at the time of first NLDN discharge to $10.5 \mathrm{~km}$ at the last LASA discharge. Figure 3 compares two current moment waveforms with the burst of gamma-rays and the initial IC flash evolution depicted by the first few LMA sources. All the signals on this plot reflect their variations at the source location.

[14] The burst of gamma-rays was produced during the 5-ms gap between the first and the second LMA sources, implying that the TGF-producing lightning process radiated substantially more weakly in the $76-82 \mathrm{MHz}$ band than the subsequent leader development. On the other hand, the measurements at distant electric/magnetic sensors indicate that this process radiated strongly between $300 \mathrm{~Hz}$ and $30 \mathrm{kHz}$. The TGF was produced in association with a sequence of 5 fast discharges superposed on a steadily building current that became detectable $2 \mathrm{~ms}$ after the first LMA source, although this current moment could have initiated earlier with magnitude below the background noise level equivalent to $\sim 2 \mathrm{kA} \cdot \mathrm{km}$. This current also persisted for about $1 \mathrm{~ms}$ after the last LASA discharge. The entire sequence produced a charge moment change of $+90 \mathrm{C} \cdot \mathrm{km}$ within $3 \mathrm{~ms}$ (positive denoting upward motion of negative charge), about twice the mean charge moment change previously reported to be associated with RHESSI TGFs [Cummer et al., 2005].

[15] Even accounting for the possible 1-2 ms uncertainty in the RHESSI timing corrected by the $1.8-\mathrm{ms}$ offset [Grefenstette et al., 2009], several robust conclusions can be drawn from the observation presented here. The TGF occurred after the IC flash onset (which might precede the first LMA source), during the early stage of an upward propagating negative leader that caused an unusually large current moment for the portion of its development close to the TGF. It is possible that the leader may have contained an atypically large electric charge around this time, which contributes to the strong electric field required to produce the TGF [Moss et al., 2006]. As shown in Figure 3, the TGF was not produced until the current moment had reached a level of $10 \mathrm{kA} \cdot \mathrm{km}$, or a current of $>5 \mathrm{kA}$ with the assumption of a $2-\mathrm{km}$ leader channel. The production of high energy photons from leader propagation is qualitatively consistent with theory [Moss et al., 2006; Dwyer, 2008] and ground observations [Moore et al., 2001; Dwyer et al., 2004] of lightning-produced energetic radiation in excess of $1 \mathrm{MeV}$.

[16] The leader was associated with intermittent fast discharging processes in $2 \mathrm{~ms}$, some of which occurred within a small fraction of $1 \mathrm{~ms}$ of the TGF. Both these impulsive discharges and the anomalously high current moment associated with the upward leader appeared to stop after the TGF production. The subsequent LMA sources show that the negative leader continued to propagate upward for several milliseconds while radiating actively at VHF in a typical manner for stepped leaders. Correlating the individual fast discharges with gamma-ray production requires greater time precision than RHESSI provides, but it remains possible the gamma-ray generation either turned on or turned off at the time of one of these discharges.

[17] Based upon the vertical progression of LMA sources, the burst of gamma-rays was produced when the leader had ascended to an altitude between 10 and $11 \mathrm{~km}$. This is consistent with the measured altitudes of TGF-associated IC discharges ranging between 10 and $15 \mathrm{~km}$ [Stanley et al., 2006]. Detailed Monte Carlo simulations, however, show that the observed gamma-ray spectra are most consistent with TGF sources at 15-21 km altitude [Dwyer and Smith, 2005]. This discrepancy of several kilometers remains an unanswered question linked to where precisely the gammarays are generated relative to the upward negative leader, which is clearly connected to the observed TGF.

\section{Summary}

[18] We have reported the observation with the North Alabama LMA related to a TGF detected by RHESSI on 26 July 2008 . The LMA data explicitly show that the TGF production was associated with the upward propagation of an energetic leader during the initial development of a compact IC flash within $30 \mathrm{~km}$ of the subsatellite point. This IC flash was confined in the convective region of an isolated storm that developed a negative charge region centered at $8.5 \mathrm{~km}$ above sea level and a positive region at $13 \mathrm{~km}$.

[19] The concurrent measurements of low frequency electric and magnetic fields at $700-800 \mathrm{~km}$ range that the TGF-associated initial IC flash development spawned a sequence of fast discharges and caused a charge moment change of $+90 \mathrm{Cokm}$ within $3 \mathrm{~ms}$. These discharges were all associated with a slowly building current moment that was most likely related to an upward leader subsequent to the lightning onset. Analysis using the RHESSI timing corrected by the $1.8-\mathrm{ms}$ offset indicates that the burst of gamma-rays was produced during the upward leader propagation, while the exact correlation between the TGF and discrete lightning discharges needs to be investigated by means of the observations with improved timing accuracy.

[20] Acknowledgments. This work was supported by NSF Physical Meteorology Program grant ATM-0221968. The authors would like to thank Bill Winn, Ken Eack, Ron Thomas, Bill Rison, and David Raymond for valuable discussions.

\section{References}

Cohen, M. B., U. S. Inan, R. K. Said, and T. Gjestland (2010), Geolocation of terrestrial gamma-ray flash source lightning, Geophys. Res. Lett., 37, L02801, doi:10.1029/2009GL041753.

Coleman, L. M., T. C. Marshall, M. Stolzenburg, T. Hamlin, P. R. Krehbiel, W. Rison, and R. J. Thomas (2003), Effects of charge and electrostatic potential on lightning propagation, J. Geophys. Res., 108(D9), 4298, doi:10.1029/2002JD002718.

Cummer, S. A., and U. S. Inan (2000), Modeling ELF radio atmospheric propagation and extracting lightning currents from ELF observations, Radio Sci., 35, 385-394, doi:10.1029/1999RS002184.

Cummer, S. A., Y. Zhai, W. Hu, D. M. Smith, L. I. Lopez, and M. A. Stanley (2005), Measurements and implications of the relationship between lightning and terrestrial gamma ray flashes, Geophys. Res. Lett., 32, L08811, doi:10.1029/2005GL022778.

Cummins, K. L., M. J. Murphy, E. A. Bardo, W. L. Hiscox, R. B. Pyle, and A. E. Pifer (1998), A combined TOA/MDF technology upgrade of the U.S. National Lightning Detection Network, J. Geophys. Res., 103, 9035-9044, doi:10.1029/98JD00153.

Doviak, R. J., and D. S. Zrnić (2006), Doppler Radar and Weather Observations, 2nd ed., Dover, Mineola, N. Y. 
Dwyer, J. R. (2008), Source mechanisms of terrestrial gamma-ray flashes, J. Geophys. Res., 113, D10103, doi:10.1029/2007JD009248.

Dwyer, J. R., and D. M. Smith (2005), A comparison between Monte Carlo simulations of runaway breakdown and terrestrial gamma-ray flash observations, Geophys. Res. Lett., 32, L22804, doi:10.1029/2005GL023848.

Dwyer, J. R., et al. (2004), A ground level gamma-ray burst observed in association with rocket-triggered lightning, Geophys. Res. Lett., 31, L05119, doi:10.1029/2003GL018771.

Fishman, G. J., et al. (1994), Discovery of intense gamma-ray flashes of atmospheric origin, Science, 264, 1313-1316, doi:10.1126/ science.264.5163.1313.

Goodman, S. J., et al. (2005), The North Alabama Lightning Mapping Array: Recent severe storm observations and future prospects, Atmos. Res., 76, 423-437, doi:10.1016/j.atmosres.2004.11.035.

Grefenstette, B. W., D. M. Smith, B. J. Hazelton, and L. I. Lopez (2009), First RHESSI terrestrial gamma ray flash catalog, J. Geophys. Res., 114, A02314, doi:10.1029/2008JA013721.

Gurevich, A. V., G. M. Milikh, and R. Roussel-Dupré (1992), Runaway electron mechanism of air breakdown and preconditioning during a thunderstorm, Phys. Lett. A, 165, 463-468, doi:10.1016/0375-9601(92) 90348-P.

Hazelton, B. J., B. W. Grefenstette, D. M. Smith, J. R. Dwyer, X.-M. Shao, S. A. Cummer, T. Chronis, E. H. Lay, and R. H. Holzworth (2009), Spectral dependence of terrestrial gamma-ray flashes on source distance, Geophys. Res. Lett., 36, L01108, doi:10.1029/2008GL035906.

Inan, U. S., S. C. Reising, G. J. Fishman, and J. M. Horack (1996), On the association of terrestrial gamma-ray bursts with lightning and implications for sprites, Geophys. Res. Lett., 23, 1017-1020, doi:10.1029/ 96GL00746.

Inan, U. S., M. B. Cohen, R. K. Said, D. M. Smith, and L. I. Lopez (2006), Terrestrial gamma ray flashes and lightning discharges, Geophys. Res. Lett., 33, L18802, doi:10.1029/2006GL027085.

Koshak, W. J., et al. (2004), North Alabama lightning mapping array (LMA): VHF source retrieval algorithm and error analyses, J. Atmos. Oceanic Technol., 21, 543-558, doi:10.1175/1520-0426(2004) 021<0543:NALMAL $>2.0 . \mathrm{CO} ; 2$.

Moore, C. B., K. B. Eack, G. D. Aulich, and W. Rison (2001), Energetic radiation associated with lightning stepped-leaders, Geophys. Res. Lett., 28, 2141-2144, doi:10.1029/2001GL013140.

Moss, G. D., V. P. Pasko, N. Liu, and G. Veronis (2006), Monte Carlo model for analysis of thermal runaway electrons in streamer tips in transient luminous events and streamer zones of lightning leaders, J. Geophys. Res., 111, A02307, doi:10.1029/2005JA011350.
Rison, W., R. J. Thomas, P. R. Krehbiel, T. Hamlin, and J. Harlin (1999), A GPS-based three-dimensional lightning mapping system: Initial observations in central New Mexico, Geophys. Res. Lett., 26, 3573-3576, doi:10.1029/1999GL010856.

Shao, X.-M., and P. R. Krehbiel (1996), The spatial and temporal development of intracloud lightning, J. Geophys. Res., 101, 26,641-26,668, doi:10.1029/96JD01803.

Shao, X.-M., T. Hamlin, and D. M. Smith (2010), A closer examination of terrestrial gamma-ray flash-related lightning processes, J. Geophys. Res., doi:10.1029/2009JA014835, in press.

Smith, D. M., L. I. Lopez, R. P. Lin, and C. P. Barrington-Leigh (2005), Terrestrial gamma-ray flashes observed up to $20 \mathrm{MeV}$, Science, 307, 1085-1088, doi:10.1126/science.1107466.

Stanley, M. A., X.-M. Shao, D. M. Smith, L. I. Lopez, M. B. Pongratz, J. D. Harlin, M. Stock, and A. Regan (2006), A link between terrestrial gammaray flashes and intracloud lightning discharges, Geophys. Res. Lett., 33 , L06803, doi:10.1029/2005GL025537.

Stolzenburg, M., W. D. Rust, and T. C. Marshall (1998), Electrical structure in thunderstorm convective regions: 3. Synthesis, J. Geophys. Res., 103, 14,097-14,108, doi:10.1029/97JD03545.

Thomas, R. J., P. R. Krehbiel, W. Rison, T. Hamlin, J. Harlin, and D. Shown (2001), Observations of VHF source powers radiated by lightning, Geophys. Res. Lett., 28, 143-146, doi:10.1029/2000GL011464.

Williams, E., et al. (2006), Lightning flashes conducive to the production and escape of gamma radiation to space, J. Geophys. Res., 111, D16209, doi:10.1029/2005JD006447.

R. J. Blakeslee, Earth Science Office, NASA Marshall Space Flight Center, 320 Sparkman Dr., Huntsville, AL 35805, USA.

D. E. Buechler, H. J. Christian, and J. M. Hall, Global Hydrology and Climate Center, University of Alabama in Huntsville, 977 Exlplorer Blvd., Huntsville, AL 35806, USA.

S. A. Cummer, J. Li, and G. Lu, Electrical and Computer Engineering Department, Duke University, Box 90921, Durham, NC 27708, USA. (cummer@ee.duke.edu; g146@duke.edu)

E. W. McCaul, Universities Space Research Association, 977 Explorer Blvd., Huntsville, AL 35806, USA.

X.-M. Shao, Space and Remote Sensing Group, Los Alamos National Laboratory, MS D436, Los Alamos, NM 87545, USA.

D. M. Smith, Department of Physics, University of California, 1156 High St., Santa Cruz, CA 95064, USA. 